\title{
Conflictos de exilio. La frontera como no lugar en La mitad del infierno de Óscar Palacios
}

\author{
Conflicts of exile. The border as non-place in $\mathrm{La}$ \\ mitad del infierno by Óscar Palacios
}

Vladimir González Roblero* (https://orcid.org/0000-0002-9317-0636)

Universidad de Ciencias y Artes de Chiapas, Facultad de Artes, Chiapas, México, correo electrónico: vlatido@gmail.com

\section{Resumen}

Este ensayo es un análisis de la novela La mitad del infierno del escritor chiapaneco Óscar Palacios, en el que se examina la representación de la frontera sur de México como no-lugar. El estudio emplea dicha categoría propuesta por Marc Augé. Con base en ella se analizan las múltiples tramas que subyacen en la novela. Además, la hermenéutica de Ricoeur sirve para entender las implicaciones ideológicas que envuelven al lector para representarse al sureste mexicano. Con base en lo anterior, la representación de la frontera sur resulta palimpsesto de lugares (histórico, relacional) donde, según las tramas, se impone la idea de no-lugar como una de las maneras de concebir los límites entre Méxicoy Centroamérica.

Aceptado el 8 de junio de 2018.

Publicado el 20 de agosto de 2018.

Palabras clave: frontera, literatura, no lugar, Chiapas.

\section{Abstract}

*Autor para correspondencia: Vladimir González Roblero, correo electrónico: vlatido@gmail.com

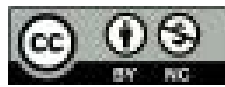

Esta obra está protegida bajo una Licencia Creative Commons Atribución-NoComercial 4.0 Internacional.
This essay is an analysis of the novel La mitad del infierno by the writer from Chiapas Óscar Palacios, in which the representation of the southern border of Mexico is examined as a non-place. The study employs this category proposed by Marc Augé. Based on it, the multiple plots that underlie the novel are analyzed. In addition, Ricoeur's hermeneutics serves to understand the ideological implications that surround the reader to represent the Mexican southeast. Based on theabove, therepresentation of the southern borderis palimpsest of places (historical,relational) where, according totheplots, theidea ofnon-placeisimposed asone oftheways of conceiving theboundariesbetween MexicoandCentralAmerica.

Keywords: border, literature, non-place, Chiapas.

CÓMO CITAR: González, V. (2018). Conflictos de exilio. La frontera como no lugar en La mitad del infierno de Óscar Palacios [Conflicts on exile. The border as non-place in La mitad del infierno by Óscar Palacios]. Estudios Fronterizos, 19, e014. doi:https://doi. org/10.21670/ref.1814014 


\section{Orientaciones sobre el no lugar y su representación}

El antropólogo francés Marc Augé publicó en 1992 un libro sugerente: Los no lugares. Espacios del anonimato. ${ }^{1}$ Sostiene que la modernidad ha acelerado el tiempo, producido un exceso de acontecimientos y de lugares, e incrementado la individualización. Esta propuesta se sostiene desde dos posiciones críticas: la primera de ellas, como ya se advierte, es a la modernidad, a la que prefiere llamar sobremodernidad por un triple exceso: 1) de tiempo o acontecimientos, porque vivimos en lo efímero, en el vértigo de una diacronía incesante cuyos acontecimientos superabundan y son cada más breves; 2) de lugar o espacios, porque las distancias en el planeta han disminuido, como si de una aldea global se tratara, y 3) de individuo, porque ante la ausencia de grandes relatos para explicar al mundo, se ha vuelto al individuo como explicación; esto a su vez, ha provocado una ausencia de referencias (Augé, 2000). La segunda crítica es al oficio antropológico. Se pregunta si el mundo moderno, inmerso en las condiciones descritas, se "presta a la observación etnológica" (Augé, 2000, p. 19). Esta preocupación le conduce a cuestionar los métodos y las teorías de la antropología. Considera que se deben abordar nuevos terrenos empíricos, objetos que se construyen al constatar una sobremodernidad que, si bien ha sido observada, no lo ha sido desde el abordaje disciplinar (Augé, 2000).

Las preocupaciones respecto a la antropología y a la sobremodernidad son el inicio de la indagación sobre los no lugares. Una de las dimensiones de la triple aceleración, la que se refiere a la sobreabundancia de espacios, conduce a Augé (2000) a elaborar la teoría del no lugar, envés del lugar antropológico. Este último tiene al menos tres características, se considera: identificatorio, relacional e histórico. Es identificatorio porque confiere sentido a quien lo habita y es constitutivo de su identidad; es histórico porque, a diferencia de los lugares de memoria, es decir, de aquellos que refieren al pasado, es resultado de una historia que sigue estando presente y que no necesita ser evocada; es histórico para quienes lo habitan aunque no sea importante históricamente y finalmente es relacional porque los cuerpos y las cosas que lo habitan configuran el espacio, relacionándose entre sí, ocupando un lugar.

Los lugares que no se pueden pensar como lugares de identidad, relacionales e históricos se definen como no lugares. La sobremodernidad los ha multiplicado y producido. El planeta se ha achicado, las experiencias ocurren breve y rápidamente y con ellas los no lugares. Son pensados como lugares de tránsito, espacios de anonimato; sus usuarios no se apropian de ellos como lo hacen con los lugares antropológicos, al contrario, su uso es perecedero. Marc Augé dice al respecto:

Un mundo donde se nace en la clínica y donde se muere en el hospital, donde se multiplican, en modalidades lujosas e inhumanas, los puntos de tránsito y las ocupaciones provisionales (...) donde se desarrolla una apretada red de medios de transporte que son también espacios habitados, donde el habitué de los supermercados, de los distribuidores automáticos y de las tarjetas de crédito renueva con las gastos de comercio de "oficio mudo", un mundo así prometido a la individualidad solitaria, a lo provisional y a lo efímero, al pasaje (Augé, 2000, pp. 83-84).

\footnotetext{
${ }^{1}$ En este trabajo se utiliza la edición del año 2000.
} 
Los aeropuertos, estaciones de tren o de autobuses, supermercados, autopistas, automóviles resultan ser no lugares. También las fronteras. En ellas observamos una particularidad: lugares y no lugares se empalman, son palimpsestos. ${ }^{2}$ Los no lugares se inscriben en los lugares. La frontera, desde esta perspectiva, es un palimpsesto de lugares. Es lógico pensar que sus nativos establecen relaciones identitarias e históricas con ella, pero tampoco es descabellado asumir que el extraño, el migrante, solo está de paso, que la considera un lugar de tránsito.

¿Cómo asumir cualquiera de las dos afirmaciones? La representación de la frontera significa evocarla a través de testimonios y de dispositivos científicos o artísticos. Esta evocación permitirá suscribir la frontera como palimpsesto de lugares, en el que una representación terminará de imponerse sobre la otra, esto implica escuchar con atención los testimonios y leer del mismo modo los dispositivos de representación. Un artículo científico, incluso una pieza periodística, tratará de representar a través de la metonimia la realidad: apegarse a su régimen de verdad, la empiria, para evocar con cierta fidelidad lo representado. Una obra de arte, literaria o de otra índole, recurre a tropos para evocar como metáfora o analogía lo representado (Beuchot, 2013).

Frente a estas lecturas es importante advertir las implicaciones ideológicas del relato, pensar la frontera como lugar o no lugar sugiere una mirada, un punto de vista, es la observación del enunciante la que intenta envolver, implicar al lector o receptor. ¿Con qué intenciones? Paul Ricoeur (2004) en su teoría de la narratividad, sostiene que lo narrado se desdobla en tres momentos miméticos: el primero, el tiempo vivido, que prefigura lo que ha de narrarse; el segundo, la configuración de la trama, que ordena la narración; y el tercero, el tiempo narrado que reconfigura las acciones. En esta operación están implicados éticamente el autor y el lector. La narración sugiere otra valoración del mundo, distinta a lo narrado, hay una intención del autor, pero también hay una motivación del lector quien asume el mundo como si lo representado fuera de ese modo. Lo anterior resulta en una especie de explicación ideológica, como sugiere Hayden White (2001) cuando analiza los entrecruzamientos de la historia y la ficción.

Estas consideraciones conceptuales - los lugares, las representaciones y las implicaciones- orientan la mirada a la frontera sur y su literatura. Este binomio, como se verá, se halla en una estructura de mayor duración, donde se entrecruza la historia con la literatura y modula una historia de la literatura.

\section{Una frontera en la narrativa de ficción en Chiapas}

El primer gesto literario en Chiapas dejó una huella de largo aliento: la publicación de la novela Una rosa y dos espinas del sancristobalense Flavio Paniagua (1991), en 1870, significó el hiato entre historia y literatura. Catalogada como novela histórica, Una rosa y dos espinas narra las pugnas entre republicanos e imperialistas, ocurridas a muy pocos años, durante la instauración del Imperio y sus ecos en el sur de México. La preocupación de Paniagua se inscribe en la tradición decimonónica literaria: el hecho artístico como instrumento ideológico, propagación de ideas y traslado del debate a

\footnotetext{
${ }^{2}$ Augé (2000, p. 84) sostiene: "El lugar y el no lugar son más bien polaridades falsas: el primero no queda nunca completamente borrado y el segundo no se cumple nunca totalmente: son palimpsestos".
} 
la ficción (Maldonado, 2017). Sus demás novelas andan el camino iniciado: sitúan los debates liberales y conservadores, incluso en el marco de las rebeliones indígenas.

La literatura local, por años, ha seguido este ejemplo. Si bien es cierto que Flavio Paniagua narró los acontecimientos del convulso siglo XIX, su siglo, otros escritores chiapanecos volvieron a él, incluso a acontecimientos todavía más lejanos, como alimento de sus ficciones. De este modo, la rebelión tzeltal de 1712 aparece como tema, principal o secundario, en novelas como Jovel, serenata a la gente menuda, de Heberto Morales (2010); el guion para teatro Los agravios de su ilustrísima, de Alfredo Palacios (1994); la ficción histórica María Candelaria, india natural de Cancuc, del historiador Juan Pedro Viqueira (1996), y el guion cinematográfico Los embustes de San Tanás, de Antonio Coello (2005).

Otros acontecimientos históricos acaecidos en Chiapas tienen un lugar en la literatura local. La rebelión tzotzil de 1869 fue tema de las novelas Florinda, otra vez de Flavio Paniagua (2003); Oficio de tinieblas, de Rosario Castellanos (1962) y Los confines de la utopía, de Alfredo Palacios (1992); la Revolución mexicana se vio retratada en La simiente del corsario, de César Coutiño (2001), Shalo de Amín Miceli (1994), Yucundo, lamento por una ribera, de Heberto Morales (2008) y la segunda parte de Los confines de la utopía, de Alfredo Palacios de 1992. El colofón de este ciclo literario, que narra los acontecimientos decimonónicos cuyos alcances configuraron al siglo xx, es la tetralogía de Eraclio Zepeda. Mayormente conocido por sus cuentos, Zepeda publicó entre 2006 y 2013 cuatro novelas históricas: Las grandes lluvias (2006), Tocar el fuego (2007), Sobre esta tierra (2012) y Viento del siglo (2013). En ellas se narra la conformación de Chiapas, sus decisiones políticas y pertenencias a la nación mexicana; las guerras intestinas que discutían los proyectos de nación, a veces liberales y conservadores, a veces centralistas y federalistas; las singularidades chiapanecas de la Revolución mexicana, así como sus alcances inmediatos en el primer tercio del siglo pasado.

La irrupción del Ejército Zapatista de Liberación Nacional también ha sido tema para novelas locales. Tal es el caso de Canción sin letra, de Heberto Morales (1999) y Nudo de serpientes, de Alejandro Aldana (2004).

Arribamos a una constante: la relación entre la historia y la literatura, los discursos impostados del novelista como historiador, la realidad representada como novela. Un estudio al respecto nos mostrará cómo, además de los discursos ideológicos, manifiestos o implícitos, una lectura hermenéutica de la Historia en la novela, dialoga de manera incesante con las corrientes historiográficas, con las teorías de la historia (Perkowska, 2008). La literatura decimonónica es cercana a la pretensión historiográfica de verdad, por lo tanto, la representación del pasado, en la historiografía, atiende a la vieja idea de mimesis emparentada con la pretensión rankeana de narrar el haber sido tal como ocurrió. La historiografía representa ese pasado desde la visión hermenéutica de la univocidad, cuya pretensión trata de ajustarse en la medida de lo posible a la referencialidad que le convoca. La teoría posmoderna de la historia se acoda mejor con otra representación, aquella que llama a la polisemia y que busca en el pasado ya no el telón de fondo, sino la historia misma abierta a los significados (Perkowska, 2008). Es el caso de las novelas cuya referencialidad es la historia.

La relación entre historia y literatura, entre hechos históricos y novela, sitúa otros acontecimientos, como los indicios de la modernidad, la vida cotidiana, la migración y la frontera en la literatura de Chiapas. Una lectura coyuntural permite articular la aparición en esta literatura sureña de temas que comienzan a arraigarse. El periodo 
de la guerrilla centroamericana, así como las dinámicas económicas, sobre todo, muestran el desplazamiento desde esos territorios hacia el norte, México y Estados Unidos, son esos desplazamientos los que la literatura ha representado. En estos últimos me detengo.

\section{La migración centroamericana}

La historia reciente de Centroamérica ha estado marcada por la violencia. El triunfo de la Revolución cubana y el avance del comunismo llamaron la atención de Estados Unidos, su política internacional, en este contexto, fue de contención. Los países centroamericanos padecieron dicha política; esto significó la injerencia norteamericana en la vida política de Centroamérica, el ascenso de dictaduras, primero, y de falsas democracias, después. Una de las consecuencias fueron los flujos migratorios de la década de 1980.

Los movimientos migratorios en Centroamérica, de acuerdo con Abelardo Morales (2007), pueden dividirse en tres momentos: el primero de ellos vinculado al desarrollo de economías fincadas en la agroexportación, el segundo a los desplazamientos forzosos ocurridos en el contexto de las guerrillas, y el tercero es relativo a los procesos de transnacionalización laboral.

Como es de suponerse, la migración es multicausal y no necesariamente implica brincar fronteras políticas. El flujo migratorio correspondiente a la economía agroexportadora se ha dado desde el siglo xix. El desarrollo de las economías de plantación requirió de mano de obra y para llegar a este momento, hubo un proceso de despojo de tierras: los indígenas fueron separados de sus propiedades y se convirtieron en peones, sus tierras se utilizaron en plantaciones y su auge demandó trabajadores; por lo tanto, los jornaleros se movieron entre territorios, de manera interna, y extraordinariamente la migración fue transfronteriza (Morales, 2007, p. 114).

El segundo momento migratorio sucede en el contexto de la guerrilla y las represiones del Estado. Los migrantes escaparon de la violencia, al principio de manera individual y después en masa. Al respecto se identifican tres fenómenos: la migración internacional, principalmente a México; los desplazados internos y los repatriados (Morales, 2007, p. 117).

Finalmente la transnacionalización laboral. Esta migración ocurre de manera paralela a los conflictos armados, pero la causa es otra. La interdependencia de las economías y sus procesos de globalización, explican las migraciones más allá de las fronteras estatales. La inserción de las economías locales en procesos globales supuso el fin del modelo agroexportador heredado, para dar paso a un modelo neoliberal. Las causas son estructurales: caída de los salarios, precarización del empleo y la venta de bancos y de otras empresas estatales. La consecuencia fue que, sobre todo en la década de 1990, se incrementó la migración por estas circunstancias, los campesinos emigraron a las ciudades y al exterior (Morales, 2007).

Me detendré en los desplazamientos forzosos. La figura del caudillo y las dictaduras centroamericanas se originan en el surgimiento y desarrollo del capitalismo agrario. La institución del poder oligárquico tuvo su envés en movimientos instituyentes, como el de Augusto Sandino, en Nicaragua, y Agustín Farabundo Martí, en El Salvador en la década de 1930 (Torres-Rivas, 2007). La derrota de los movimientos populares de 
entonces instauró a los militares en el poder prácticamente hasta la década de 1980 (Torres-Rivas, 2007).

Hacia la década de 1960, después del triunfo de la Revolución cubana y la expansión del comunismo, la política norteamericana impulsó el crecimiento económico de Centroamérica y estableció estrategias de democratización política. Lo hizo a través del programa Alianza para el Progreso (ALPRO), que consistía en proporcionar ayuda económica a países latinoamericanos. Edelberto Torres-Rivas (2007) llama a los regímenes que emanaron de aquí como "democracias de fachada" que consistieron en el ascenso de militares al poder a través de elecciones periódicas, cuya función fue legitimar las dictaduras. "A la elección presidencial concurrían varios candidatos pero sólo ganaba el general nominado por el Ejército” (Torres-Rivas, 2007, p. 102).

Las democracias de fachada se establecieron en Guatemala, El Salvador y Nicaragua. En estos países los sectores opositores, integrados sobre todo por campesinos, universitarios, sindicalistas y políticos reformistas, fueron duramente reprimidos, mientras que los grupos empresariales se fortalecieron y jugaron un importante papel al instaurar prácticas y discursos políticos. El contexto favoreció la movilización social y no tardaron en aparecer grupos armados o estallidos revolucionarios. Los escenarios fueron Honduras, El Salvador, Nicaragua y Guatemala; Costa Rica, sin embargo, tuvo la capacidad de construir un "Estado capaz de estimular el crecimiento y el desarrollo" (Torres-Rivas, 2007, p. 107).

En Nicaragua se fundó en 1961 el Frente Sandinista de Liberación Nacional. El movimiento combatió la dictadura de Somoza; encontró aliados en la burguesía a partir del asesinato de Pedro Joaquín Chamorro. En Guatemala se organizaron varios frentes contra la dictadura: se fundan las Fuerzas Armadas Rebeldes, aparece el Partido Guatemalteco del Trabajo y se organizan el Ejército Guerrillero de los Pobres y la Organización del Pueblo en Armas, los cuales se amalgaman en la Unidad Revolucionaria Guatemalteca. La dictadura de este país fue dura frente a estos movimientos guerrilleros; asesinó a activistas, estudiantes, campesinos, periodistas. Las acciones estatales, su combate, ocasionaron miles de desplazados, sobre todo indígenas, lo que ha sido calificado como la mayor matanza étnica de la historia en América Latina. En El Salvador el panorama pintó similar; en 1970 se fundaron las Fuerzas Populares de Liberación y el Ejército Revolucionario del Pueblo y posteriormente se unifican para formar el Frente Farabundo Martí de Liberación Nacional (Torres-Rivas, 2007).

\section{Literatura de la frontera sur}

El contexto descrito es la coyuntura que permite entender la migración hacia el sur de México. La región conocida como Soconusco ha sido lugar de asiento o de tránsito para los migrantes, pero además, esta coyuntura comprende la reciente producción literaria local y mexicana, cuyos hacedores no la han desapercibido.

La narrativa de ficción chiapaneca cuenta las historias del trauma. Sobre el trauma histórico, Dominik LaCapra (2009 y 2005) sugiere que su narración es una línea delgada entra la historia y la ficción. Los historiadores y novelistas habitan esta frontera, sobre todo porque el acontecimiento traumático es un hecho histórico que muchos preferiríamos olvidar (LaCapra, 2005). Paul Ricoeur (2006, pp. 909-912), 
por su parte, cuando aborda en sus reflexiones la identidad narrativa, explica que la ficción se pone al servicio de la historia para contar acontecimientos memorables, es decir, dignos de recordar, o execrables, es decir, que no deberíamos olvidar. La historia se ficcionaliza al contar estos acontecimientos como epopeyas positivas o negativas, mismas que confieren identidad a los pueblos.

La idea de trauma suele utilizarse para calificar algún acontecimiento que conmociona a la persona o a un pueblo, o también, como acontecimientos ocurridos en algún pasado, cercano o lejano, y que gozan de actualidad (Sanfelippo, 2011). ¿Por qué el trauma es motivo de la literatura del sur de México? Pareciera que este trauma está vinculado a la historia centroamericana: considero que es posible abordar lo anterior desde la idea identidad, que de acuerdo con Gilberto Giménez (2009), se construye relacionalmente, es decir, con los otros, y es posible acercarse a su comprensión a partir de la identificación de elementos de distinguibilidad: la pertenencia a pluralidad de colectivos, el reconocimiento de atributos idiosincráticos y las narrativas biográficas. Estas unidades distinguibles, en el caso de la frontera sur, son intercambiables para sostener una identidad nacional y una identidad cultural. Al respecto, es necesario decir que la identidad nacional, según Valenzuela (2015, p. 93) "remite a la dimensión ideológica que implica la identificación con un proyecto de nación”. En el caso de la identidad cultural, es pertinente acercarse a ella desde la construcción de las regiones. De acuerdo con Young (1992) una región se compone de regionalidad, "la cualidad de ser región" y regionalismo "la identificación consciente, cultural, política y sentimental que grandes grupos de personas desarrollan con ciertos espacios a lo largo del tiempo" (Young, 1992, pp. 432). Lo anterior me permite sostener que en el sur de México existe una identidad nacional, construida desde la hegemonía de la nación mexicana, artificialmente como consecuencia de la incorporación de Chiapas a esta nación en el siglo xix. Al mismo tiempo existe una identidad cultural en el espacio de una región, pues la frontera sur comparte cualidades como la selva y la montaña, pero también unidades distinguibles comunes que no se han construido políticamente, sino culturalmente: modismos, música, grupos étnicos, gastronomía e historia, por nombrar algunos. La convergencia de la identidad mexicana como nacional, y la regional como cultural, es lo que llamo identidad fronteriza.

Si una de las unidades de distinguibilidad es la narrativa biográfica, el sur de México ha participado de manera tangencial en la historia reciente y directamente en la historia lejana de Centroamérica. LaCapra (2009) sostiene que los efectos del evento traumático no los padecen exclusivamente las víctimas, sino que, de manera diferente, afecta también "a cualquiera que entre en contacto con él: victimario, colaboracionista, testigo, resistente, los nacidos a posteriori” (LaCapra, 2009, p. 21). Recordemos que Centroamérica y el sur de México fueron un proyecto histórico común. La provincia de Chiapas, en la época colonial, perteneció a la Capitanía General de Guatemala junto con San Salvador, Nicaragua, Honduras y la gobernación de Costa Rica (Gutiérrez, 2004, p. 13). Cuando en 1821 comienzan las luchas independentistas de las colonias españolas, Chiapas se mantuvo a la expectativa. Al momento de decidir, lanzó su proclama de independencia. El primer obstáculo que hubo de sortear fue una decisión mayor: debido a las condiciones de pobreza había de buscar integrarse al proyecto de la república de Centroamérica o a México (Gutiérrez, 2004). Finalmente, después de intensas discusiones, las élites locales prefirieron a la nación mexicana. Este pasado centroamericano no ha dejado de permear en la actualidad; la cultura chiapaneca, sus modos de hablar, su música, 
guardan relación con la centroamericana, especialmente la guatemalteca. No por ello se supone la identidad centroamericana sino más bien fronteriza.

Resabios de este pasado común se asoman en la producción literaria local. Si he mencionado a Flavio Paniagua como el primer escritor chiapaneco, fue porque su novela Una rosa y dos espinas apareció en 1870, cuando Chiapas se había ya integrado a esa entelequia que llamamos México. Pero al mismo tiempo la literatura guatemalteca publicaba novelas históricas de hechos ocurridos en Chiapas, tal fue el caso de la novela de Agustín Mencos Franco, publicada en 1898, titulada Don Juan Núñez García, que recrea la rebelión tzeltal de 1712, desde entonces la literatura de la frontera sur ha compartido temáticas y preocupaciones, entre ellas, según Jesús Morales (2005), hallamos que los espacios narrados son predominantemente rurales, la selva sobre todo; la cuestión indígena también permea en ella; las rebeliones, motines e insurrecciones campean, incluyendo las recientes ocurridas a partir de la década de 1970.

Entonces el trauma es común a la región histórica. Las novelas son lugares de memoria porque su lectura nos guía al pasado, ${ }^{3}$ o sitios de trauma, como lo explica LaCapra (2009, p. 23):

Un sitio de memoria es generalmente también un sitio de trauma y que en la medida en que permanezca investido con las marcas del trauma marca hasta qué punto no ha logrado la memoria captar el trauma, sobre todo a través del duelo.

Traumática ha sido la historia reciente de Centroamérica: el mayor genocidio de la América Latina reciente; el desplazamiento de muchos de sus habitantes, quienes han visto en la frontera mexicana una esperanza (Morales, 2005). La literatura opera como estrategia de recuperación de la memoria histórica, del trauma compartido. Alfredo Palacios Espinosa (2005) ha escrito un texto dramático titulado Limites perdidos, que cuenta la historia de un grupo de refugiados en la frontera. El fondo de la historia alude a conflictos de identidad, sobre los que se desarrolla una historia amorosa como imposible. El tema también ha sido recurrente en la literatura de Nadia Villafuerte. Su colección de cuentos Barcos en Houston (2005) constituyen el inicio de un camino literario por los senderos fronterizos; por este mismo andar transcurren las historias de ¿Te gusta el látex, cielo? (2008) y su novela Por el lado salvaje (2011). Otro escritor chiapaneco, Gabriel Hernández García, escribió Lejanías (2008), novela que relata el estigma que define al indocumentado centroamericano.

No puedo dejar de mencionar La mara (2011) novela de Rafael Ramírez Heredia. La referencialidad alude al fenómeno de las culturas juveniles centroamericanas, explicadas por las condiciones estructurales económicas, políticas y sociales. Esto se traduce en violencia, tráfico de drogas y pandillerismo, cuyo sitio de ocurrencia es la porosa frontera a lo largo del río Suchiate, específicamente entre Tecún Umán y Ciudad Hidalgo.

Las obras literarias referidas hablan de la condición del migrante y de la frontera, que son fenómenos sociales enlazados a la realidad centroamericana, a su pozo histórico. La guerrilla centroamericana en estos países es el fondo que da pie a la historia de la novela La mitad del infierno de Óscar Palacios, de la que hablaré a continuación.

\footnotetext{
${ }^{3}$ Cuando Pierre Nora (2008, pp. 23-24) se refiere a los lugares de memoria, lo hace a partir de la distinción de la historia. Ésta, como representación del pasado, obvia los lazos vividos que unen a las personas y a los pueblos con ese pasado. Son esos lazos que tratan de mantenerse como vínculos, por eso, dice Nora, los lugares de memoria son artificios que salvan a la memoria de los olvidos de la historia.
} 


\section{La mitad del infierno}

Óscar Palacios nació en 1942 en Yajalón, Chiapas. Es poeta, narrador y dramaturgo. Su producción literaria, que arranca hacia finales de la década de 1960, se ha caracterizado por abordar temáticas diversas, entre ellas, las relacionadas con posiciones y discursos sociales y políticos. Al menos dos novelas se inscriben en una de las vertientes de la tradición literaria chiapaneca: el vínculo con la historia lejana o reciente; por ejemplo En memoria de nadie (1982) y La mitad del infierno (1993).

En memoria de nadie es una novela de 1982 cuya historia no es inventada sino hallada en el pasado del sur mexicano. Trata del asesinato de un líder sindical yucateco, Efraín Calderón, alias "Charras". Su muerte ocurrió en 1974 en Mérida, ciudad con la que Palacios guarda relación al estudiar ahí la carrera de abogado.

La mitad del infierno se publicó por primera vez en $1990 .{ }^{4}$ La novela sitúa la historia entre los años 1982-83, en el Soconusco, región mexicana fronteriza con Guatemala. Fue la época de la dictadura del presidente guatemalteco Efraín Ríos Montt, el único personajes histórico al que se hace referencia, nombrado como el general Arroyos Mon. Su gobierno se caracterizó por una represión hacia sectores sociales, universitarios y sindicalistas, así como a grupos indígenas. Fue juzgado y condenado por genocidio en el año 2013; posteriormente la sentencia fue anulada debido a irregularidades en su proceso (Vásquez y Hernández, 2013).

En el universo ficticio la referencia a Ríos Montt es importante. Explica el viaje que ha iniciado uno de los personajes, Álvaro Vidal, guatemalteco, recién egresado de la carrera de Derecho. Su arribo a tierras mexicanas se debió a la represión del gobierno, quien tomó la universidad porque suponía que "se había llenado de comunistas" (Palacios, 1993, p. 18). La travesía hacia México ocurre en compañía de otro migrante: Óscar Figueroa. Salvadoreño, mulato, este personaje tiene como objetivo seguir más al norte, hasta Estados Unidos. En el Soconusco, específicamente en la ciudad de Huixtla, lugar donde suceden varias de las acciones, los personajes centroamericanos encuentran a dos mexicanos: don Gonzalo, recaudador de Hacienda, quien funge como ayudante a los viajeros; y Teresa Luviano, terrateniente, dueña de la finca El Desengaño, quien sostiene un romance con Álvaro.

La mitad del infierno es la historia de estos cuatro personajes, mientras que las acciones suceden en lugares que se traslapan. Como señala Augé los lugares antropológicos y los no lugares están imbricados como palimpsestos. En la novela se representa una frontera como lugar antropológico, cuyos habitantes se apropian de él como asidero de identidad y de historia. Sobre este se impone el no lugar: un espacio de tránsito, representado como tal por los migrantes y sus proyectos. Las cuatro historias de los personajes se empalman también, pero la trama trágica se impone sobre las tramas secundarias. El efecto que se produce, desde esta perspectiva, es la representación de la frontera como no lugar.

\footnotetext{
${ }^{4}$ Esta edición fue en el Programa Cultural de las Fronteras. Otras ediciones son de 1993, en el Instituto Chiapaneco de Cultura; 2009, en el Colegio de Bachilleres de Chiapas, y en 2015, reunida en un volumen de tres novelas, en editorial La otra. La edición que consulté para este trabajo es la de 1993.
} 


\section{La frontera como lugar}

Me gustaría iniciar el análisis de la representación de la frontera como un lugar antropológico. Si recordamos a Augé, este se caracteriza por ser identificatorio, relacional e histórico. A continuación observaré la historia ficticia y el espacio fronterizo como lugar.

En La mitad del infierno uno de los personajes que sirve para pensar el lugar antropológico es don Gonzalo. Representa este lugar porque su visión de la frontera es el equilibrio, no mira en ella el conflicto, al contrario, su función en el mundo narrado es guiar a los dos migrantes; su relación amistosa es importante para que Álvaro permanezca por un lapso de dieciocho meses en Huixtla y varios de ellos como capataz de la finca El Desengaño. Óscar, por su parte, no logra en ningún momento establecerse y se emplea en trabajos diversos hasta que don Gonzalo le obsequia el boleto de avión que le permite, por fin, viajar a Estados Unidos.

Las acciones de este personaje ofrecen una mirada conciliadora sobre la frontera. Si el lugar antropológico es constitutivo de identidad, el siguiente pasaje lo sugiere, dice don Gonzalo:

Hace veinte años llegué a este pueblo... acepté, sin ninguna práctica para ello, ser colector de rentas. Hoy le dicen recaudador o delegado. Acepté este tipo de trabajo, tan alejado de mi realidad, porque era lo único que me ofrecía un querido amigo y yo necesitaba comer y tener el espacio vital para escribir. El tema que había imaginado se desarrollaba en este prodigio de fecundidad que es el Soconusco (p. 26).

No necesariamente es una mirada idílica; hay, eso sí, una identificación con el espacio, el adjetivo "prodigio de fecundidad" lo sugiere. En otros lugares de la narración, este mismo personaje pone el acento crítico y cómico a la frontera ya que la travesía por la que guía a los migrantes incluye borracheras épicas. Al final de ellas la imagen que devuelve la frontera no es, en apariencia, agreste ni violenta. ${ }^{5}$

Otra característica del lugar antropológico es su dimensión histórica. Como lo ha señalado Augé es distinto al lugar de memoria. Pierre Nora considera que los lugares de memoria son espacios donde "se cristaliza y refugia la memoria" (Allier, 2008, p. 88). En el lugar antropológico, al contrario, la memoria no es refugio. Esta característica no evoca un pasado sino más bien se vive en ese pasado. Uno de sus personajes, Teresa Luviano, sirve para entender la relación histórica con el lugar; en el mundo ficcional, Luviano es dueña de El Desengaño, la finca de café más importante de la región, asimismo, su familia, además del poder económico que ya se advierte, está relacionada con las esferas del poder político, han ocupado la presidencia municipal de Tapachula, la ciudad fronteriza de mayor desarrollo en el sureste. Ella misma tendrá esa posibilidad.

${ }^{5}$ Así se expresa esta condición: "Bien, comemos un taco por ahí y después nos vamos a uno de los lugares más sui géneris de la costa chiapaneca: la zona de tolerancia.

Álvaro se queda sorprendido del comentario. Sonríe y aborda la camioneta. Van rumbo al mercado, donde las carnes asadas de doña Chenta tienen fama en el lugar. Ahí se detienen y mientras esperan, una cerveza helada está recorriendo las gargantas acaloradas de don Gonzalo y Álvaro. Es la hora nona. La hora en que el fuego parece salirse de las calles de concreto" (p. 29). 
$\mathrm{Al}$ respecto, el narrador dice:

La finca El Desengaño, antes con un hombre de ciudad alemana, dejaba ver el poderío de los Luviano, un poderío establecido cuando los precios del "oro verde" habían aumentado, gracias a que Brasil tiró su cosecha al mar para mantener los precios del mercado. Lo había logrado el viejo Luviano. Padre de Tereso Luviano y abuelo de los actuales propietarios: Alberto, Teresa y Estrella, cuando los primeros dueños de la finca retornaron en la vejez a su país de origen, dejando al viejo Luviano como administrador (p. 32).

Aquí se explica el origen del poder que ostentan los Luviano, pensar en estos términos nos lanza al presente, mientras el guiño al pasado es un recurso que nos ayuda a comprender en el tiempo de la acción la importancia de una familia de terratenientes. Este es el poder que tratan de mantener y perpetuar. El hermano de Teresa, Alberto, se mueve en el ámbito de la política; es él quien arregla la candidatura de ella a la presidencia municipal, lo que les permitirá continuar con la hegemonía política y económica de la familia.

Este presente histórico se relaciona directamente con el lugar, no es solo con la finca sino también con el Soconusco, pero también, hay otro pasado que reefectúa al presente. Se trata de la violación a Teresa Luviano ocurrida en la finca de la cual es propietaria.

Alberto, su hermano:

Con mano temblorosa tomó la sábana para cubrirla y se detuvo un instante para apretar suavemente el pezón izquierdo y de ahí suavemente, con los ojos dibujados entre una mirada de duda y de lujuria, siguió en cada mano en cada uno de los senos... la sangre de su juventud cerró los ojos a la razón y se acostó junto a Teresa, se desabrochó la bragueta y como fiera en celo acometió con furia, como queriendo romper todo su miedo y su vergüenza, un largo gemido entre dolor y placer inundó la estancia (p. 43).

La escena y el acto rondan la actualidad de Teresa y alimentan sus miedos e inseguridades. La violación significa también el trauma histórico, pero este trauma no es el recuerdo, se experimenta como lo vivido en el presente. El lugar antropológico es simbolizado también como violencia. Augé describe la relación histórica evocando un pasado sin conflictos, y proyecta al presente como un lugar cómodo, pero no siempre es así. La historia de Teresa Luviano simboliza una frontera donde el abuso de poder es cotidiano; es la cultura patriarcal que se impone donde mujeres centroamericanas se emplean en los prostíbulos. Ya Nadia Villafuerte ha notado esta condición en su literatura, también es la violencia que se expresa en el pandillerismo y en la discriminación hacia el migrante, de lo que las novelas de Rafael Ramírez Heredia y Gabriel Hernández son ejemplo.

Las historias de don Gonzalo y Teresa Luviano son distintas pero no se excluyen. La primera de ellas, con matices, sugiere una frontera posible, donde sus habitantes se sobreponen al conflicto, sin embargo, la segunda es una historia conflictiva como callejones sin salida. En su conjunto ambas formas de tramar sugieren la frontera como lugar antropológico. 


\section{La frontera como no lugar}

Las tramas en La mitad del infierno devienen representaciones de lugares y no lugares. Si las historias de los personajes mexicanos ofrecen una mirada de la frontera como espacio creado, es decir, instituido, las de los migrantes centroamericanos no alcanzan esta condición; con ellos se configura el no lugar. Estas dos representaciones no se excluyen, de este modo, la contraposición que aparenta es solo una ilusión: un lugar es un no lugar, pero depende de la apropiación de sus usuarios. El mismo territorio albergará esta doble condición, en este sentido, los lugares son posibilidades. En la novela el no lugar se reinscribe en el lugar antropológico, más aún: se impone.

Las características del no lugar se definen en relación al lugar. Un territorio que no sea histórico, ni relacional ni provea de identidad será un no lugar. La triple aceleración de tiempo, de espacio y de individuos resulta en la sobreabundancia de lugares, de acontecimientos y de individualidades, esto permite la proliferación de los no lugares; son espacios de anonimato donde sus usuarios, debido a estas condiciones, generalmente están de paso, luego entonces, los habitué son efímeros en tanto no alcanzan apropiarse del lugar, por eso, según Augé (2000), el viajero es el arquetipo del no lugar. En tanto viajeros, debemos distinguir al turista del migrante; el primero viaja por placer, su actitud es de contemplación (Navarrete, 2014); el segundo por necesidad, desplazado de su lugar de origen (Feldman-Bianco, Rivera, Stefoni y Villa, 2011) y lo hace de manera regular o irregular (García, 2015).

En el universo ficcional de La mitad del infierno el viajero es sujeto migrante, los personajes huyen de sus países por motivos de la dictadura y las luchas guerrilleras. Álvaro Vidal es perseguido político y Óscar Figueroa escapa de la leva, ellos son quienes están de tránsito en la frontera; sus proyectos son distintos pero en ninguno hay una apropiación en términos históricos e identitarios del Soconusco.

La frontera como no lugar aparece en las tramas que se construyen alrededor de estos dos personajes, se manifiesta como conflictos de exilio. En primer lugar, la historia amorosa entre Álvaro Vidal y Teresa Luviano. A través de ella se rastrean conflictos identitarios, posiciones ideológicas y de clase encontradas, todas ellas como condiciones que configuran la breve estancia en México. En segundo lugar la historia de Óscar Figueroa, personaje cómico, cuyo tránsito es efímero en la frontera, quien mientras busca llegar a Estados Unidos se emplea en los trabajos más variados y asume su paso como festivo.

La historia principal está tramada en tragedia. Al respecto Hayden White (2001, pp. 18-19) sostiene: aquí, en la tragedia, "no hay ocasiones festivas, salvo las falsas e ilusorias"; esta concluye con "la caída del protagonista y la conmoción del mundo en que vive". La historia es el romance de Álvaro y Teresa. En ellos la tensión fronteriza está desde el principio: él guatemalteco, ella mexicana; él universitario de ideas progresistas, ella terrateniente acostumbrada a ejercer el poder; él con resentimiento de clase, ella opresora. Esta dualidad implica una idea manida de frontera como límite y no como espacio común, de hecho, la relación inequitativa persiste en la novela desde el momento mismo que el guatemalteco se convierte en el capataz de la finca El Desengaño.

Ahí, en la finca, comienza el romance y ahí mismo los conflictos de exilio, como atestigua este diálogo entre don Gonzalo y Álvaro: 
-(Teresa) Es extraña, muy extraña; se da y se retira, bloquea sus sentimientos (dice Álvaro).

-Una golondrina no hace verano.

-Esta es una golondrina que anidó dentro de mí.

-No te dejes llevar por tus conflictos de exilio.

-No es eso, creo que Teresa...

-No crees nada; estás solo, en la montaña, ella es una mujer atractiva.

-Pero si se dio el encuentro ¿por qué me ignora?

-No te ignora a ti, se ignora a ella. Siempre ha estado huyendo de no sé qué. Tómalo con calma, sólo el hoy debe importarte, tu mañana no está ahí. Vamos... (p. 81).

Los conflictos de exilio imposibilitan la relación afectiva hacia la frontera. Estos conflictos, muchos de ellos en el ámbito de lo privado, brincan a la esfera pública. La relación amorosa se vuelve un escándalo y visibiliza también las disputas identitarias. La tragedia comienza a perfilarse a partir de la intervención de Alberto Luviano. “¿Cómo te atreves a exhibirte con ese cachuco muerto de hambre?", dice Alberto a Teresa (p. 104). Junto a este personaje la idea de frontera como no lugar también se aclara, su aparición desestabiliza la relación amorosa. Este derrumbe concluye con el rompimiento y con la sentencia de Teresa a Álvaro: "tú te vuelves a tu territorio y yo me quedo en el mío" (p. 121).

La historia trágica se impone sobre las tramas secundarias, pues simboliza la idea de frontera como no lugar porque sucede a uno de los personajes migrantes; su estancia en la frontera es breve como lo fue la relación amorosa. La travesía entonces no cesa. Ambos protagonistas asumen con resignación el destino: ella acepta con desgano postularse a la presidencia municipal de Tapachula mientras él regresa a Guatemala, mientras tanto, el migrante centroamericano no alcanza a apropiarse del espacio como lugar antropológico, el destino proyecta un lugar efímero.

La segunda historia es la de Óscar Figueroa, el salvadoreño. Aunque no guarda el mismo desarrollo ni la intensidad que la historia de Álvaro Vidal, su trama es cómica. El personaje se sitúa en un contexto de violencia, la frontera, en el que sus acciones resultan fuera de lugar. En la historia, casi como anécdotas, se narran sus empleos, borracheras y terquedades. "Sólo loco o borracho se puede vivir aquí", dice (p. 58). Pero un propósito se asoma. Al escapar del reclutamiento forzado que se vivía por parte del Ejército salvadoreño, el personaje se empecina en llegar a Estados Unidos; aunque no es la primera vez que lo intenta, sus esfuerzos solo alcanzaron la frontera norte. Una y otra vez es regresado a Suchiate, el límite con Guatemala. De vuelta a esta frontera deambula por los distintos pueblos, empleándose como Máscara mortal, luchador profesional; como ayudante de chofer o como amante; el siguiente pasaje lo describe:

- Me quedé unos días con mi gorda en Cachoatán, después bajé a Tapachula y todo iba bien hasta que hubo salida rumbo al norte, llegué a Arriaga, con tan mala suerte que en el restaurant donde comimos... iba de ayudante de un camionero, hubo bronca con unas gentes que eran de la "migra", me madrean, me meten al bote, me regresan a Frontera Hidalgo y antesito de llegar me tuve que echar a un cabrón de "la migra" para que me dejara de este lado.

—Lo mataste -dice sorprendido Álvaro. 
—Ja, ja, ja, ¡no macho!, me salió "manflor" y me lo pisé para que me soltara (p. 56).

Del mismo modo como he advertido que el lugar antropológico no siempre es consenso, el no lugar tampoco es sinónimo de conflicto. La comedia es una mirada crítica a la realidad social (Sánchez, 2005) y también es una estrategia de resistencia (Scott, 2007). La historia cómica de Óscar Figueroa configura un no lugar por su condición de paso. Las relaciones que establece son efímeras, quizá a sabiendas que su destino está en otro lado. El hecho de ser distinta de la historia trágica no significa que estas se excluyan. Se complementan sobre todo al entender que su propósito no ha fracasado. Al final don Gonzalo le obsequia un boleto de avión que lo pondrá de cara a la frontera norte y tiempo después se informa que por fin ha llegado a Estados Unidos. El hecho de alcanzar el objetivo — situación que no sucede con el guatemaltecoconstituye el sentido de la errancia. La frontera sur fue solo transitoria.

La historia de los migrantes, cuyas tramas son distintas, están articuladas por el viaje. El sujeto del no lugar es el viajero. A través de ellos una de las representaciones de la frontera, la que se impone sobre la otra, permite mirarla como un espacio de anonimato, incluso más allá.

Si volvemos a la idea de las tramas, por eso varios matices de representaciones, se afianza una idea teleológica. La novela se sitúa en la frontera mexicana y muy pocas veces hace referencia al lado guatemalteco. Cuando pasa ofrece una visión desigual. De este lado, el mexicano, el consenso; del otro, el conflicto. La dualidad parece difuminarse cuando se piensan los dos lados como lugar común, esto sucede cuando Álvaro regresa a su lugar de origen. El personaje asume que ese lado, el suyo, es la mitad del infierno; el otro se ha quedado del lado mexicano, y no es solamente el geográfico.

\section{Conclusión}

La representación de la frontera como lugar y no lugar tiene sus implicaciones. Tanto las obras literarias como las historiográficas se explican y comprenden con sus propios regímenes de verdad. Estos dos tipos de obras, sin embargo, se hallan unidas en el reino del relato, su aproximación en tanto construcción narrativa es hermenéutica. La obra historiográfica ofrece una lectura cercana a la verdad histórica. La obra literaria ofrece una lectura de lo verosímil. En este sentido, las obras literarias con referencias históricas son problemáticas.

La historicidad que se halla en La mitad del infierno la coloca en esta disyuntiva. La frontera como lugar antropológico es tal debido a que el Soconusco es un lugar histórico con todo lo que ello implica. La representación de la frontera como no lugar es una posibilidad y en la novela existe esta yuxtaposición de lugares, se trata de un palimpsesto: uno estable y otro efímero.

Los matices de representación me conducen a otra implicación, la cual refiere a lo ideológico. El autor implica al lector a mirar más allá de la novela, es decir, a mirar la frontera con sus matices. El lector se ve envuelto en otras miradas al mundo que no son necesariamente propias. Desde esta perspectiva, pensar la frontera como lugar antropológico, o como no lugar, es una sugerencia sobre los modos de interpelar al mundo. 
Por otro lado casi al mismo tiempo que Marc Augé publicaba el libro Los no lugares aparecía La mitad del infierno. Esta simultaneidad complicaría la apropiación teórica para el análisis, sin embargo, es importante notar que los no lugares no son fenómenos exclusivos de la sobremodernidad. Una interpretación del pensamiento de Herder nos conduce al siglo XviII como uno de sus orígenes. Al abordar el problema de la pertenencia a, Herder (Berlin, 2000) sostiene que la historia, la lengua y la cultura ha permitido a los hombres arraigarse a su centro vital, es decir, a un territorio; de este modo, un exiliado no se siente como en casa, pues no se sitúa en el mismo arroyo de la historia, lengua y cultura. La idea contraria a la pertenencia a la nación y su territorio, como sugiere la oración anterior a esta, sin duda encaja en lo que Augé ha considerado un no lugar. Por otro lado, el diseñador urbano Melvin Webber empleó el término en 1964. Lo hizo para referirse a "los espacios inauténticos, repetitivos e impersonales" de las grandes ciudades (Navarrete, 2014). Con ello anunciaba la descolocación de la civitas, es decir, de la comunidad de ciudadanos que habitan las ciudades (Choay y Urrieta, 2009). Lo que Marc Augé advirtió, en resumen, fue la sobreproducción de lugares mas no la aparición de nuevos lugares.

La frontera tampoco es propia de la sobremodernidad, su construcción es histórica. Una idea de frontera nos remite al confín, la tierra de nadie (Fábregas, 2005). El inicio de la expansión europea remarcó y amplió las fronteras al consolidar la disputa por el planeta, la construcción de los Estados nacionales son muestra de ello. Desde entonces estas tierras de nadie han sido no lugares. La sobremodernidad las ha expuesto y también ha construido nuevos confines.

En este sentido, La mitad del infierno es una representación de los límites históricos entre México y Guatemala como no lugar.

\section{Referencias}

Aldana, A. (2004). Nudo de serpientes. México: El Animal.

Allier, E. (2008). Lugar de memoria: ¿Un concepto para el análisis de las luchas memoriales? El caso de Uruguay y su pasado reciente. Cuadernos del CLAEH, (96-97), $87-109$.

Augé, M. (2000). Los no lugares. Espacios del anonimato. Una antropología de la sobremodernidad. Barcelona, España: Gedisa.

Berlin, I. (2000). Vico y Herder. Dos estudios en historia de las ideas. Madrid, España: Cátedra.

Beuchot, M. (2013). Perfiles esenciales de la hermenéutica. México: Fondo de Cultura Económica.

Castellanos, R. (1962). Oficio de tinieblas. México: Joaquín Mortiz.

Choay, F. y Urrieta, S. (2009). El reino de lo urbano y la muerte de la ciudad. Andamios, 6(12), 157-187.

Coello, A. (2005). Los embustes de San Tanás. México: Coneculta.

Coutiño, C. (2001). La simiente del corsario. México: Fraternidad Corzo.

Fábregas, A. (2005). El concepto de frontera: Una formulación. En A. Basail (Coord.), Fronteras des-bordadas. Ensayos sobre la Frontera Sur de México (pp. 21-51). México: Universidad de Ciencias y Artes de Chiapas. 
Feldman-Bianco, B., Rivera, L., Stefoni, C. y Villa, M. I. (2011). La construcción social del sujeto migrante en América Latina: Prácticas, representaciones y categorías. Quito, Ecuador: Clacso, Flacso, Universidad Alberto Hurtado, Govern de les Illes Balears.

García, M. del C. (2015). La migración irregular de tránsito desde el derecho y la política en el tiempo global. El caso de México. En M. E. Anguiano y D. Villafuerte (Coords.), Cruces de fronteras. Movilidad humana y políticas migratorias (pp. 52-81). México: El Colegio de la Frontera Norte, Universidad de Ciencias y Artes de Chiapas.

Giménez, G. (2009). Materiales para una teoría de las identidades sociales. En G. Giménez, Identidades sociales (pp. 25-51). México: Conaculta.

Gutiérrez, S. N. (2004). Chiapas histórico: De la independencia a la revolución, 1821-1920. México: Secretaría de Educación.

Hernández, G. (2008). Lejanias. México: Universidad de Ciencias y Artes de Chiapas.

LaCapra, D. (2005). Escritura de la historia, escritura del trauma. En L.G. Morales (Comp.), Historia de la historiografía contemporánea (de 1968 a nuestros días) (pp. 443-490). México: Instituto de Investigaciones Dr. José María Luis Mora.

LaCapra, D. (2009). Historia y memoria después de Auschwitz. Buenos Aires, Argentina: Prometeo libros.

Maldonado, D. (2017). Entre verdad y ficción: Una rosa y dos espinas, de Flavio A. Paniagua y el imperio en Chiapas, de Manuel B, Trens (Tesis). Universidad de Ciencias y Artes de Chiapas, Tuxtla Gutiérrez, Chiapas, México.

Miceli, A. (1994). Shalo. México: Nuñez Díaz editor.

Morales, A. (2007). La diáspora de la posguerra: regionalismo de los migrantes y dinámicas territoriales en América Central. San José, Costa Rica: Flacso.

Morales, H. (1999). Canción sin letra. México: Coneculta.

Morales, H. (2008). Yucundo, lamento por una ribera. México: Universidad Intercultural de Chiapas.

Morales, H. (2010). Jovel, serenata a la gente menuda. México: Coneculta.

Morales, J. (2005). La frontera sur en su literatura. Notas para su estudio. En A. Basail (Coord.), Fronteras des-bordadas. Ensayos sobre la Frontera Sur de México (pp. 53-85). México: Universidad de Ciencias y Artes de Chiapas, Casa Juan Pablos.

Navarrete, D. (2014). Los No lugares y la arquitectura del espacio turístico. Revista Interiorgráfico de la división de Arquitectura Arte y Diseño de la Universidad de Guanajuato. Recuperado de https://www.interiorgrafico.com/edicion/decimo-cuarta-edicion-octubre-2014/los-no-lugares-y-la-arquitectura-del-espacio-turistico

Nora, P. (2008). Pierre Nora en Les lieux de mèmoire. Santiago, Chile: Lom ediciones y Trilce.

Palacios, A. (1992). Los confines de la utopía. México: Gobierno de Chiapas, Instituto Chiapaneco de Cultura.

Palacios, A. (1994). Los agravios de su ilustrísima. Memorial dramático en tres actos. México: Instituto Nacional Indigenista.

Palacios, A. (2005). Limites perdidos. México: Coneculta.

Palacios, O. (1982). En memoria de nadie. México: Gaceta editores.

Palacios, O. (1993). La mitad del infierno. México: Instituto Chiapaneco de Cultura.

Paniagua, F. (1991). Una rosa y dos espinas. México: Gobierno del Estado de Chiapas.

Paniagua, F. (2003). Florinda. México: Universidad de Ciencias y Artes de Chiapas. 
Perkowska, M. (2008). Historias híbridas. La nueva novela histórica latinoamericana (19852000) ante las teorias posmodernas de la historia. Madrid, España: Iberoamericana-Vervuert.

Ramírez, R. (2011). La mara. México: Alfaguara.

Ricoeur, P. (2004). Tiempo y narración. Configuración del tiempo en el relato histórico. México: Siglo XxI.

Ricoeur, P. (2006). Tiempo y narración. El tiempo narrado. México: Siglo xxI.

Sánchez, A. (2005). Invitación a la estética. México: Grijalbo.

Sanfelippo, L. (29 de septiembre de 2011). El trauma en la historia. Razones y problemas de una importancia conceptual. Recuperado de http://usagespublicsdupasse. ehess.fr/el-trauma-en-la-historia-razones-y-problemas-de-una-importacion-conceptual/

Scott, J. (2007). Los dominados y el arte de la resistencia. Discursos ocultos. México: Era.

Torres-Rivas, E. (2007). La piel de Centroamérica: Una visión epidérmica de setenta y cinco años de su historia. San José, Costa Rica: Flacso.

Valenzuela, J. M. (2015). Identidades culturales: Comunidades imaginarias y contingentes. En J. M. Valenzuela (Coord.), Decadencia y auge de las identidades. Cultura nacional, identidad cultural y modernización (pp. 89-110). México: El Colegio de la Frontera Norte.

Vásquez, B. y Hernández, M. (20 de mayo de 2013). CC anula condena a Efraín Ríos Montt. Prensa libre. Recuperado de http://www.prensalibre.com/noticias/justicia/CC-deliberando-resolucion-Rios-Montt_0_922707981.html

Villafuerte, N. (2005). Barcos en Houston. México: Coneculta.

Villafuerte, N. (2008). ¿Te gusta el látex, cielo? México: Conaculta.

Villafuerte, N. (2011). Por el lado salvaje. México: Ediciones B.

Viqueira, J. (1996). María de la Candelaria, india natural de Cancuc. México: Fondo de Cultura Económica.

White, H. (2001). Metahistoria. La imaginación histórica en la Europa del siglo XIX. México: Fondo de Cultura Económica.

Young, E. (1992). La crisis del orden colonial. Estructura agraria y rebeliones populares de la Nueva España, 1750-1821. México: Alianza editorial.

Zepeda, E. (2006). Las grandes lluvias. México: Fondo de Cultura Económica.

Zepeda, E. (2007). Tocar el fuego. México: Fondo de Cultura Económica.

Zepeda, E. (2012). Sobre esta tierra. México: Fondo de Cultura Económica.

Zepeda, E. (2013). Viento del siglo. México: Fondo de Cultura Económica.

Vladimir González Roblero

Mexicano. Historiador y comunicólogo, doctor en Ciencias Sociales y Humanísticas por la Universidad de Ciencias y Artes de Chiapas (Unicach). Actualmente es profesor investigador en la Facultad de Artes de la Unicach, México. Líneas de investigación: "Historia y Literatura", en la que investiga la representación de procesos históricos en el arte, la literatura y la historiografía; e "Historia de la cultura, periodismo y políticas culturales en Chiapas", en la que investiga la incidencia de las políticas culturales en las prácticas y discursos culturales y artísticos. Su trabajo publicado más recientemente es el capítulo "Novela histórica y levantamientos indígenas en Chiapas. Andamio para la construcción de un siglo histórico literario". 